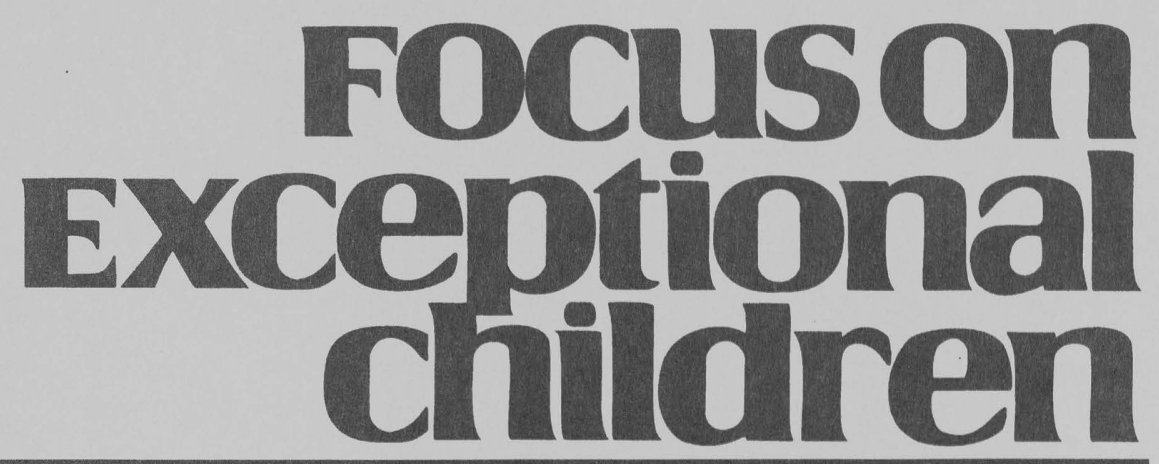

\title{
School-Family Collaboration: A Partnership
}

\author{
Lawrence J. Johnson, Marleen C. Pugach, and Annie Hawkins
}

One of the most important goals that schools can undertake is to develop healthy partnerships with families. A truly collaborative school can be achieved only through active and positive partnerships with families. Our students are all members of families first and students second. Family members are so interrelated that any individual experience that affects one member will affect all. Families are going to have the most lasting and powerful influence on the development of the students with whom we work. Consequently, to be able to lay the groundwork for effective collaborative relationships, we must understand families.

Traditionally, the image of family was perceived as father, mother, and two or more children living together. Actually, few American families now fit the traditional image (Zinn \& Eitzen, 1993). Fewer than one in five families currently fits the more traditional notion of two parents and children. The U.S. Bureau of Census (Scoon-Rogers, 1999) reports that over the past 25 years, the number of families headed by single men has increased from 1.3 million to 3.2 million and families headed by single women has increased from 5.8 million to 13.6 million. One explanation is a divorce rate that has doubled, along with widowing and adoption. Many families consist of step-parents and step-siblings, extended families, common-law families, communal families, serial families, or some combination thereof (Beirne-Smith, Ittenbach, \& Patton, 1998). Our notion of the family has to expand to acknowledge the unique pressures of the various types of family units with which teachers will come in contact. The new types of living arrangements often bring unique problems that include everything from blatant discrimination to social stigma (Edwards, 1995).

In this article we provide a framework from which to interpret and understand the unique demands being placed on the family. We must understand families and their unique dynamics as a foundation for our efforts toward developing collaborative relationships with the families of the students. Unless we understand families and their unique needs and pressures, attempts at collaboration will be susceptible to misunderstanding. After we have provided this foundational context, we explore real and perceived barriers that can inhibit collaboration among teachers and families. Finally, we provide practical suggestions

\footnotetext{
Lawrence J. Johnson is the Dean of the School of Education at the University of Cincinnati. Marleen Pugach is a professor in the Department of Curriculum and Instruction at the University of Wisconsin at Milwaukee. Annie Hawkins is with the School of Education at the University of Cincinnati. This article was adapted from Collaborative Practitioners Collaborative Schools published by Love Publishing Company.
} 
regarding ways to collaborate more effectively with the families of students.

\begin{abstract}
As you read this article, take a minute to think about the different types of families with whom you have had more than casual contact. How do they interact, solve problems, experience joy, and so on? They could be families of close relatives, your family, or the families of friends. As you think about these families, identify three or four families with different structures and styles. As you read about families, ask yourself how the issues discussed relate or play themselves out with each of these families. Focus on similarities and differences as you think about these families.
\end{abstract}

\title{
THE FAMILY
}

The basic unit that defines and sustains our society is the family. The family consists of two or more individuals who meet the collective and individual needs of family members. These people may or may not be related by blood or marriage and may or may not usually live together (Turnbull, Turnbull, Shank, \& Leal, 1995). The family unit is one of the most basic forms of human organization. Although the family has changed dramatically over the last 25 years, it

\section{Focuson
Exceptional children}

ISSN 0015-511X FOCUS ON EXCEPTIONAL CHILDREN (USPS 203-360) is published monthly except June, July, and August as a service to teachers, special educators, curriculum specialists, administrators, and those concerned with the special education of exceptional children. This publication is annotated and indexed by the ERIC Clearinghouse on Handicapped and Gifted Children for publication in the monthly Current Index to Journals in Education (CIJE) and the quarterly index, Exceptional Children Education Resources (ECER). The full text of Focus on Exceptional Children is also available in the electronic versions of the Education Index. It is also available in microfilm from Xerox University Microfilms, Ann Arbor, MI. Subscription rates: individual, \$36 per year; institutions, \$48 per year. Copyright (C) 2004, Love Publishing Company. All rights reserved. Reproduction in whole or part without written permission is prohibited. Printed in the United States of America. Periodical postage is paid at Denver, Colorado. POSTMASTER: Send address changes to:

$$
\begin{gathered}
\text { Love Publishing Company } \\
\text { Executive and Editorial Office } \\
\text { P.O. Box } 22353 \\
\text { Denver, Colorado } 80222 \\
\text { Telephone (303) 221-7333 }
\end{gathered}
$$

Edwin Ellis

University of Alabama
Tim Lewis University of Missouri

Chriss-Walther Thomas

University of Kansas

Susan T. Warhover Editor
Stanley F. Love Publisher continues to have as its primary purpose meeting family members' needs to nurture their fullest development. Although families differ across cultures, commonalities among family units worldwide are far greater than their differences. As Moles (1993) has asserted, what parents want for their children is universal.

The family can be defined as a network of people who live together for an extended time because of mutual commitment to the family unit. This commitment can be by blood, marriage, legal means, or otherwise. The type of commitment or how this commitment is made is less important than the fact that a commitment has been made. What is important is the mutual partnership among family members. Families exist in a number of forms or varieties, all of which are able to meet the needs of family members. Some forms are:

1. Traditional nuclear family: parents and children.

2. Single-parent family: one parent or guardian (male or female) and children. That parent might be single as a result of many factors: death, divorce, never married, adoptive, or desertion.

3. Blended family: adults (married or not) and children from previous marriages or unions.

4. Extended family: nuclear family unit plus grandparents, aunts, uncles, cousins, and so on.

5. Same-gender couples: with and without children.

\section{FAMILY SYSTEMS}

As a system, the family is made up of members and a series of subsystems that are internally and externally related. If anything affects one family member, it will affect the rest of the family system. Similarly, changes in the broader structural system of the family also will affect the family. For example, a bad economy can create stress that can strain the family system and influence how a child functions in the classroom. In a similar fashion, what happens at school can affect the broader family unit. For example, a child who receives a detention or some kind of school discipline also may be disciplined at home. If one of the adult members of the family considers this discipline to be too harsh, the marital subsystem is stressed. More specifically, when we ask family members to spend extra time with one of their children supporting classwork, the additional time they are spending with this child will detract from other activities within the family. Although requests for support typically have positive outcomes, the extra time we ask family members to work with the child can do more harm than good if the family is already stressed by spending long hours supporting the family.

As stated previously, the idea of a typical family is no longer applicable to today's family unit. Nevertheless, a framework is in place for understanding the family as a 
series of subsystems. We propose the following four subsystems, modeled after Turnbull and Turnbull (2001):

1. Adult-adult subsystem: partner interactions between the adults in the unit, whether married or not

2. Parental subsystem: parent and child interactions

3. Sibling subsystem: child and child interactions

4. Extended family subsystem: interactions of nuclear family relatives and others who are regarded as relatives.

The interaction between subsystems depends greatly on the structure of the larger family unit. For example, singleparent families have no adult partner subsystem, and families with only one child have no sibling subsystem. A discussion of these subsystems follows.

\section{Adult-Adult Subsystem}

The adult-adult subsystem is composed of the two primary adults within the family unit, regardless of their marital status. These adults have needs and roles as adult partners. They plan for the family, support one another, play together, and share intimacy.

\section{Parental Subsystem}

The parental subsystem is composed of the adult primary caregiver(s) and the children. The caregiver(s) assume a wide variety of roles as they interact with the children within the family. Roles include counselors, financial advisors, chauffeurs, disciplinarians, tutors, and so on. These roles can be explicit or implied and are fluid and constantly changing. The primary adult caregiver may be a single individual, a couple of individuals, or more.

\section{Sibling Subsystem}

The sibling subsystem is made up of interactions between children within the family unit. According to Powell and Gallagher (1993), siblings are socialization agents who provide children's first and most intense peer relationships. A sibling sometimes takes on a parental role within the family and interacts more like a parent than a sibling. Siblings may be step-siblings, half-siblings, natural siblings, or adoptive siblings.

\section{Extended Family Subsystem}

The extended family subsystem consists of members of the family beyond the immediate family members. Interactions with extended family can be a source of support or they can be a source of additional stress. Some extended families provide a great deal of support, and others have become estranged because of their geographic location or for other reasons. As a result, these families do not have a natural support system upon which to rely. Families without extended families must create an analogous support system from friends and neighbors. Unfortunately, some families are unable to create such a support system.

\begin{abstract}
Next we are going to discuss basic family needs. As you read this section, think about the families of students in your class or practicum. Are some families having trouble meeting their basic needs? How does this affect children at school? Could the school do anything to help the family meet its needs? Is the school responsible for helping families meet their needs? Are there any pitfalls for schools providing resources to enable families to be better able to meet their needs?
\end{abstract}

\section{FAMILY FUNCTIONS}

The tasks in which families engage to meet the needs of family members are called family functions. Each family function is affected by every family member. This influence may be positive, negative, or neutral (Barnett \& Boyce, 1995; O'Conner, 1995). Turnbull and Turnbull (2001) have described seven family functions:

1. Economic needs

2. Daily care needs

3. Socialization needs

4. Recreational needs

5. Self-esteem needs

6. Affection needs

7. Educational and vocational needs.

Families implement these functions to meet their current and individual needs and to transfer the responsibility of meeting those needs from the older generation of the family to the younger generation of the family. We as professionals must understand these family functions and how they relate to the family. All too often we focus on families' educational and vocational needs and ignore their other needs. Families are extremely complex, with diverse needs that must be met for the family to be effective. These needs are explored next, along with ways in which professionals can help families meet those needs.

\section{Economic needs}

All families must make decisions about how to obtain and spend money to meet the family's needs. Difficulty meeting economic needs places tremendous stress on the family unit. This stress can accentuate negative behaviors of family members and strain their interactions. Maintaining a supportive environment is difficult when basic needs are not being met. If a family has a child with a disability who requires special needs and care, the consumption demands on the family can increase greatly as a result of additional costs associated with medical care or restrictions on the ability of family to generate resources.

Schools can do many things to help. A school can collect 
information and resources on financial planning and place these in a family resource library. A school can contact appropriate local resources to provide parents with unique information in the community, such as employment services and financial planning. The school's parent organization could identify special speakers to address financial planning and saving for college and other economic concerns that may be causing concern to parents within the schools. Parents who have been successful in addressing issues such as planning for college could be asked to speak to other families that are experiencing similar problems. Secondary schools can help families become aware of scholarships and other ways to help with planning for college.

\section{Daily Care Needs}

Perhaps the most important function that a family performs is meeting the daily care needs of family members. Cooking, cleaning, doing laundry, transporting, obtaining appropriate medical care, and so on, typically dominate the family's life. As with economic needs, if the family's medical and domestic care needs are not being met, the family will have trouble focusing on other issues. When parents are trying to meet the daily care needs of their family, they often overlook their own needs and become exhausted.

When a family is having difficulty meeting daily care needs, the school might provide information on health care services in the area as part of its resource library. This information should include resources for psychological information as well as physical health care needs. The school can introduce health promotion into the curriculum. If the school has a school nurse, he or she could work with parents to develop programs for the family. Some schools have washers and dryers to assist families in the most serious need. A simple but effective action is to investigate food served at the school to ensure that it is consistent with best thinking about nutrition. Parents who have been successful in juggling the many demands placed upon them to meet daily care needs of their children can share with other families actions that have helped them be successful.

\section{Socialization Needs}

The ability to socialize is a critical component of the quality of life in any family. Families with children who have disabilities or behavior problems can be severely limited in their options to socialize because of the stress the family faces when the child is in public.

School professionals can do several things to aid families' socialization options. Respite options can be developed for families that have a child with severe disabilities. People who are skilled in dealing with the child's disability might provide child care as well as provide socialization and recreation options. The school could provide workshops on behavior management, focusing on strategies to deal with inappropriate behavior in public. Schools can encourage family support groups as a means for families to socialize with other family members. Finally, the school can reconceptualize itself as a community center and offer workshops and other community activities, providing a way for families to interact with other families in the community.

\section{Recreational Needs}

We all need activities to unwind and divert our attention from the routine of our daily lives. The family is a primary source of recreational opportunities for family members. Recreational needs are met through everything from planned structured vacations to simple walks or conversations during dinner. The school's efforts to provide for families' social needs can double as a venue for meeting their recreational needs.

\section{Self-Esteem Needs}

A sense of confidence and self-worth are integral to our identity as individuals. The family is perhaps the most important system to help people develop their sense of self-identity. We must realize that the self-identity of parents is tied heavily to the abilities of their children. For example, if a child is having difficulty in school, family members might internalize a sense of responsibility for the problem and have feelings of inadequacy themselves. Helping parents identify and pursue their own interests is one way to help them nurture their selfidentity. Finding ways for parents to participate and be successful within the school is important, too. Family support groups again can help families address their concerns in relation to other families experiencing similar concerns.

\section{Affection Needs}

Families provide a vital environment for individuals to experience affection and physical intimacy. The family provides physical as well as emotional messages that communicate unconditional regard and love to members. These messages are communicated through both verbal and nonverbal means. Nonverbal actions such as touching, hugging, kissing, or just being with one another are extremely powerful.

Although we are inclined to believe that meeting the affection needs of families is beyond the scope of schools, the school can do some things to help families address these needs. For example, schools can make accurate information on sexuality accessible to students and families. Information on AIDS and other sexually transmitted diseases is especially important for students. Counselors or support groups can be helpful to students as they confront issues of affection.

\section{Educational and Vocational Needs}

The educational and vocational needs of the family probably 
represents the area most often emphasized by professionals. Many demands are being placed on families for their time and efforts. We must be sensitive to the kinds of demands being placed on the parents and recognize that the child is only one of those demands. As a result, families must be able to choose their level of involvement within the school. If the educational/vocational needs of the family are not being met, it is extremely difficult for the family to be more involved in the school. The actions described in the section related to addressing a family's economic needs could easily be expanded to include educational and vocational needs.

\section{ELEMENTS OF FAMILY INTERACTIONS}

The extent of cohesiveness or adaptability of the family has a significant impact on the quality of interactions within the family subsystem. Cohesion is the emotional bond between members of the family, and adaptability is the ability of a family to modify or change in response to outside pressures (Olson, 1980).

\section{Cohesion}

Cohesion can be conceptualized along a continuum, with high disengagement at one end and high enmeshment at the other end. A healthy family maintains a delicate balance between the degree of disengagement and enmeshment, and this balance often shifts as new issues confront the family. For example, when a family is confronted with a crisis, it typically becomes more enmeshed. On the other hand, when a high school graduate is trying to strike out on his or her own, the healthy family becomes more disengaged.

\section{Enmeshment}

Families that are highly enmeshed often are characterized by overinvolvement and overprotection of family members. Typically, family members are allowed little privacy, and most activities of family members take place within the family. A family that becomes too enmeshed will have a difficult time functioning effectively. In particular, members will have trouble developing a sense of individuality. A certain degree of enmeshment is healthy and positive, providing a safety net that allows individuals within the family to feel supported and bolstered by the other family members. This environment can provide a foundation to encourage risk taking and growth. If the family's level of enmeshment becomes stifling, however, it will stifle risk taking and inhibit members from growing as individuals.

\section{Disengagement}

Families that are highly disengaged are characterized by underinvolvement, few common interests, excessive privacy, and long periods of separation. These families rarely discuss indi- vidual decisions, and activities of family members are seldom family-focused. Disengaged families typically have rigid subsystem boundaries, and members of the subsystem have difficulty interfacing with another subsystem. For example, one of the children may have a new girlfriend whom the siblings are aware of, but the parents have no idea of this relationship.

As with enmeshment, some disengagement is healthy for family members. If individuals within a family are to develop autonomy and independence, they must have interests outside of the family. This is particularly true as children reach their teen years and are making the transition into adulthood. Recognizing that each member within the family needs time away from other family members enables younger family members to grow. If a family becomes too disengaged, though, family cohesiveness can be seriously compromised, resulting in family members' not feeling bolstered or supported by other family members.

\section{Adaptability}

Adaptability refers to the family's ability to adjust family roles and routines to new situations. Like cohesiveness, adaptability ranges along a continuum from rigid to chaotic. Some families are extremely rigid and have great difficulty adapting to new situations. Other families are extremely chaotic and have little structure or apparent planning. In a functional family, as the needs of the family evolve, the family becomes more rigid or more chaotic to be able to better address the situation. A family must develop a balance between structure and chaos.

For example, rigid families typically have many strictly enforced rules and a clear power hierarchy. Roles within the family are extremely well defined and inflexible. The emphasis on power and control can stifle the individuality of family members and inhibit appropriate risk taking. This type of family also has difficulty dealing with crises outside of the family's rules and expectations.

Some structure and predictability, however, help children develop self-discipline. Children must learn that their actions can have negative or positive consequences. For this learning, consequences must be applied in a consistent and predictable manner. Actions that warrant negative consequences must result in negative consequences, and actions that warrant positive consequences must result in positive consequences. Through structure and predictability children develop an internalized set of limits that contribute to their self-discipline. If, however, the rules become rigid and unbending, children learn a narrow view of justice, often equated with external controls. Rigid family systems stifle risk taking and inhibit development of self-discipline and worth. Children within such a system typically become dependent upon external rather than internal controls for their behavior.

In contrast, chaotic families have little control and structure. 
They have few rules, and those rules seldom are reinforced. Promises and commitments often are not kept, and family members learn at an early age that they cannot count on one another. This type of family lacks a hierarchical role structure of family members and subsystems. As a result, roles and role expectations are uncertain and confusing. This ambiguity around roles can be a source of tension among family members.

On the other hand, appropriate chaos within the family is healthy. The most positive aspect of chaos is flexibility. The notion that roles can change within the family and that rules can be negotiated help children learn a greater sense of fairness that takes into consideration the unique circumstances of a situation. Without clear leadership and distinct roles, however, children sometimes learn a sense of helplessness or fail to develop self-reliance and self-regulatory behaviors because they have an external locus of control (BeirneSmith, Ittenbach, \& Patton, 1994). They believe they have little control over things that happen to them; no matter what they do, it doesn't seem to make a difference because outcomes seem to be independent of their actions.

\section{EFFECTIVE FAMILY INTERACTIONS}

Although functional families vary greatly in general structure and organization, certain characteristics of families do seem to enhance their ability to be functional. These characteristics, described by Luterman (1991), are as follows.

1. Communication among family members is clear and open. They discuss issues clearly, and direct personal comments to the appropriate individual. Messages are congruent with content and feeling.

2. Although roles and responsibilities of family members are clearly delineated, the family has the flexibility to address unique situations. For a family to run effectively, it must have clear boundaries that members of the family understand. Expectations and roles must be clearly articulated and fulfilled. At the same time, the family must be flexible enough so roles can be shifted to meet unique challenges of the family.

3. Family members accept limits and participate in resolving conflicts. Conflict is a healthy part of any family, and effective families resolve conflict at an individual level through fair and open means. Conflict is not denied, nor are the needs of one individual considered paramount to the needs of the family unit or other individuals within the family. Rather, resolution is sought in which all family members can feel committed. Often these families have successful face-saving mechanisms that allow all family members to feel as if they were partially successful in resolving the conflict.

4. Intimacy is prevalent and is a function of equal power transactions. A primary feature of the family is to pro- vide intimacy to members. Human beings need an environment of closeness and caring with other humans. Intimacy must be based on an equal power transaction and is not something to be demanded. All members within the family must feel free to share intimacy based on their own individual needs as well as the needs of the family unit as a whole.

5. There is a healthy balance between change and stability. Families must provide a stable foundation for members within the family and at the same time be willing to adapt to new challenges. A healthy family makes changes to accommodate challenges facing the family while still providing stability for members within the family.

\begin{abstract}
In the next section you will read about barriers that can inhibit collaborative efforts with families. As you read this section, think about these barriers and identify those you have experienced and those you have heard about from other teachers. In retrospect, could you have avoided or overcome the barrier? Have you ever changed one of your actions because a colleague or a supervisor suggested that one of the barriers described below would prevent you from being successful?
\end{abstract}

\section{BARRIERS TO FAMILY PARTICIPATION}

Serious barriers must be overcome if we are to collaborate effectively with the families of our students. Many of these barriers are merely perceived, and others are grounded in fact. Lynch and Stein (1987) studied these barriers from both a parent and a professional perspective. Parents identified barriers to participation with schools related to issues including logistics (work, time conflicts, transportation problems, and child care), communication problems, misunderstanding of schools that creates feelings of inferiority, and uncertainty about their child's unique problems. Professionals identified barriers that related to issues such as parental apathy, lack of release time and other time, lack of expertise of professionals, and feeling overburdened and devalued. A discussion of some of these perceived barriers follows.

\section{Barriers Identified by Parents}

\section{Logistical Problems}

Families sometimes have substantial logistical problems in trying to arrange for transportation, babysitting, or time away from work to attend conferences or meetings within the schools. These are serious problems that, if recognized, schools can help families overcome. For example, rather than having family members meet within the school, teachers might consider going to the family's home or meeting in a community center near the family's home. Or the school could arrange transportation for a family member to come to the school. The school could provide child care so family members could bring their children and attend meetings or 
observe in their child's classroom. Child care is relatively inexpensive and is an important means of support for parents who wish to be more involved in the school. Meetings can be held at times that are easiest for parents, such as during the lunch hour or in the evening. Another factor that alleviates time concerns is to conduct meetings efficiently. We must recognize that families have many serious time demands and, by using time efficiently, we can maximize the time spent with parents and families.

\section{Communication Problems}

Families often come from cultural or socioeconomic backgrounds different from school personnel-which can make communication more difficult. Given current demographic trends, these differences are likely to increase. When educational jargon and abbreviations enter the mix, teachers and family members might well be speaking two related but different languages with different vocabularies and styles. As a result, we may think we understand each other but actually have completely different understandings of the same conversation.

Compounding the differences are the different communication styles within a family. Some represent individual differences, and others are culturally defined. For example, some families are loud and emotional in their responses to one another, and other families are reserved and restrained. A teacher might interpret a mother's loud and emotional response as aggression, for example, whereas if the teacher were to understand the family's communication norms, he or she might interpret the mother's responses as demonstrating concern for her child.

When attempting to create and maintain effective communication with families, nonverbal communication (facial expressions, body language, eye contact, amount of personal space required, and the way one listens) must be considered. Listening is an especially important part of communication with families because it can relay the value that school personnel place on input from the family, as well as how much effort the listener is giving to understanding what the family believes is important.

Developing good communication skills and developing rapport and understanding with the families in your school's community are pivotal. In this way, family members and school personnel can enter a trusting partnership centering on student growth and achievement.

\section{Lack of Understanding of Schools}

Schools are complex organizations that have both overt and covert rules of operation. Rules can be formal (including the rights of parents of children with a disability), or they can be subtle and covert (such as the ways by which parents can influence who will be the teacher of their child). If a family member does not understand these rules, he or she may be confused and can get lost in the bureaucracy. As a result, the family member will be unable to use the system to meet the family's needs, or more specifically the child's needs, thereby compounding the sense of disenfranchisement. Having a diminished sense of control in decision making creates a feeling of inferiority and contributes to families' vulnerability to intimidation. Often, families of low-income students and students of color are the ones who feel this diminished sense of control.

To become family-focused, schools must make public their rules of operation and work to ensure that families understand these rules. A first step to becoming more familyfocused is for schools to examine what it is about their typical way of doing business that is preventing parents or other family members from being full partners in the educational process. Emphasis must be placed on encouraging families to be an integral part of what is happening within the school. In many cases this means teaching families how to access all of the resources schools have to offer. It also means recognizing that nearly all families represent an educational resource that can enrich the school experiences of all students (Moll, Amanti, Neff, \& Gonzalez, 1992), and valuing this resource.

We must create an environment and structure that empowers families. We must recognize that when we are talking to parents about concerns and challenges their children are facing, parents have a sense of responsibility that can affect their interpretation of what we are communicating.

\section{Barriers Identified by Professionals}

\section{Parental Apathy}

Although in a few schools parents may be apathetic or indifferent about being involved, school personnel often seriously exaggerate this attitude, particularly with respect to families of minority students. Sometimes the experiences that parents have had with schools have not been positive, so the parents avoid interactions because they expect all interactions to be equally negative. Second, parents may believe that they have very little influence or power over what is going to happen to their children, that no matter what they do, it won't make a difference, so why bother (Beirne-Smith et al., 1998). Third, cultural norms may dictate that the teacher is to be respected above all and that teachers know what is best. Therefore, what could families have to say about school to the experts? Finally, what we are interpreting as apathy on the part of parents might actually be exhaustion from the many demands on the family in addition to school.

To combat what is perceived erroneously as apathy, educators must get their own biases under control and not use stereotypes as an excuse to exclude parents. To say "families don't care" is easy when, in fact, scheduled meetings are not responsive to demands placed on families in terms of finding child care, taking time away from work, and getting trans- 
portation to attend meetings. When schools are unresponsive to families' day-to-day pressures, the families might say that "schools don't care." Educators must try to make schools family-centered so the activities associated with the schools generate a positive feeling with positive outcomes. If parents experience schools as positive places where positive things happen, they are much more likely to become actively engaged.

Finally, and most important, families' lack of involvement can be overcome by having families be real decision makers within the schools. To give families the appearance of being involved through representation on committees and attendance at key meetings is not enough. We must do everything we can to empower them to be vital decision makers within our schools. As families see that their participation has positive outcomes, they will be less likely to feel uncomfortable participating in the schools.

\section{Professional Time Constraints}

Like parents, professionals have a limited time to meet with parents during the school day. As a result, schools are regularly scheduling alternative meeting times such as after school and on weekends. An often overlooked concern for these meetings is the burden placed on teachers to be away from their own families for evening or weekend meetings with family members. We must get creative and develop unique ways to meet the needs of both the teachers and the families they serve. We must begin to think of new ways for teachers and parents to get together. In addition, as previously discussed, efficiently conducted meetings greatly enhance the limited time available for meetings.

We also must check and be honest about our true attitudes toward family participation. We have not always valued the input that families have to offer. Although we have consistently claimed that families are important members of our "team," our actions often convey a very different picture. When families make suggestions that are contrary to the school's views or are critical of the school, these families are often characterized as problem makers. This is particularly true if the family culture is not White and middle-class or if family members are assertive in their input. By scheduling meetings at inconvenient times, we communicate to families that they are not important. How meetings are conducted also can communicate to families that they have lower status than the other participants.

For example, in a typical IEP meeting everybody brings and shares formal information about the child. This information might include test scores, observation data, work samples, and the like. All participants at the meeting then make a formal presentation of this information to the other members of the group. Family members typically are not asked to bring any formal information, nor are they asked if they have anything to add. This communicates clearly that

\section{FOSTERING FAMILY INVOLVEMENT BY MEETING FAMILY NEEDS}

The James E. Biggs Early Childhood Education Center is located in Covington, Kentucky, across the Ohio River and essentially part of the Cincinnati, Ohio, metropolitan area. This is an urban neighborhood populated largely by families of low socioeconomic status and of diverse backgrounds. People in the community have many problems and concerns but, like all people, they care a great deal about their children and have many hopes and dreams for their future. Traditional approaches to involving families in their child's program generally have not resulted in long-term, positive effects in this community. As a result, the administration at the James E. Biggs Center decided to take a different approach to involving families and began to take steps to conceptualize and implement a family-centered program.

Rather than being child-centered, the administration decided that activities of the center must be directed to the whole family. As they began thinking about the family as its responsibility, the nature of the center began to change. The center developed a program for medical and dental care support and a family room to which parents and their children could come. Child care and transportation are provided for parents who want to volunteer or participate in an educational program. A whole series of programs and activities emerged to support families, including make-up classes, Dad's night out, weight classes, GED classes, a clothing exchange, and parentteacher training. As a result of these efforts, families are actively involved in the program.

On any given day, one can find parents in the classroom, children receiving day care, and parents just dropping by the center to sit awhile in the parent room. Clearly, families are actively involved in the program and the program is responsive to their needs. The school has become more than a school and is thought of as a central component in the community. Where many others have failed, the James E. Biggs Center has been successful by letting go of old approaches and embracing new thinking. Rather than focusing on how to get families more involved, they worked to meet the needs of families in the community. As a result, more families got involved.

family members are not full participants. The structure of the committee and the information required from the members send the message that family members have a different, less important role than the other participants.

Our actions and words regarding family involvement often communicate an incongruent message. Our actions suggest that families are not equal members while our words suggest that they are. We must work extremely hard to ensure that our actions and words are consistent. If families are 
equal members of the team, they should be treated as equals.

\section{Professional Expertise}

Working with colleagues in a collaborative manner is hard work that requires a special set of skills to facilitate communication. Working with and supporting families is equally difficult and requires specific skills. Unfortunately, these skills have not always been part of our teacher preparation programs. Becoming proficient in communication skills will provide the foundational skills necessary to be an active partner with families. We must recognize the important role of families in providing professionals with the expertise and knowledge required to work effectively with families. Until schools become truly family-centered, any reform effort is likely to fall far short of its potential. Although we have a long way to go, many notable examples can guide us.

In this example, an early childhood center has made the transition successfully from a student-centered to a familycentered program. The dominant theme at this school is the mutual respect and partnership between the family and the school. The center was able to make this transition by directing efforts toward meeting the needs of families in the school and avoiding the trap of engaging only in traditional forms of parent involvement. The strategies we discuss next can be used to help establish and nurture an environment that encourages mutual respect and cooperation.

\section{STRATEGIES FOR COMMUNICATING WITH FAMILIES}

Several strategies have been set forth for communicating with families. Although all of the strategies we describe below are important, none will be successful unless you first build a good relationship with students' families. Handbooks, announcements of special occasions, newsletters, regular progress reports, occasional notes, and telephone conferences (Turnbull \& Turnbull, 2001) are all effective only to the extent that you have worked hard to connect with families and have made the relationship between teacher, school, and family a priority for all. Therefore, we begin with strategies for establishing relationships at the start of the year, then continue with other strategies for communication. In any communication with families whose first language is other than English, you will have to translate written materials or have a translator present for face-to-face or telephone interactions.

As you read about strategies to collaborate with families, ask yourself how you can incorporate these strategies into your practice. Have you implemented some of these strategies already? Do some aspects of your approach have to be modified? Do you currently do some things that are successful that we have not discussed? Most important, how can these and other strategies help you to nurture an envi- ronment that encourages mutual respect and cooperation between you, the school, and the families your school serves?

\section{Establishing Initial Relationships With Families}

The most important foundation for communicating with families is to establish relationships with them as soon as the school year begins. There is simply no substitute for teachers' taking the time initially to introduce themselves to their students' primary caregivers and to communicate their desire to be in touch. Initial phone calls also provide teachers with an opportunity to ask family members if they wish to share anything special with the teacher about their child as the new school year begins.

Although phoning each child's family at the start of the year may seem like a daunting task, it is an essential part of every teacher's job. If a family does not have a telephone, you can send home a personal letter in the mail at the start of the school year. Some teachers send each student in their classes a postcard a few weeks before school begins. This communicates to families your level of commitment and caring even before their child steps into your classroom. If you cannot reach family members by phone and have trouble getting family members to respond to letters, you might plan a home visit with the school's parent liaison, social worker, or another teacher.

Collaboration can be successful only if lines of communication are open. Waiting to make a first family contact until a problem arises is a sure-fire way to create negative feelings. Teachers who are serious about collaborating with families take the time to establish positive relationships based on open lines of communication as soon as the school year begins.

\section{Handbooks}

Another way to help families understand what you will be doing with their child and how they can support you at home is to give them a handbook describing your rules, philosophy, major activities, a typical day in your class, and so on. Going over this handbook at the beginning of the year gives families an overview of the classroom and a concrete basis for them to ask questions.

\section{Announcements for Specific Situations}

When you have special activities or special events within your classroom, sending home an announcement describing the purpose of the activity and how family members can expand upon the activity is a good way to communicate with them. You also can send out announcements periodically about classroom activities and points of interest that might be useful to families. These might include upcoming local education events or other tips that can extend school activities. 


\section{Newsletters}

One of the most time-honored ways of communicating with families is a regular newsletter. Newsletters can be developed by the teacher, the class, the school, or other family members of students in the classroom. Newsletters are a means of providing information on upcoming events and highlighting specific accomplishments of children or a class.

\section{Regular Progress Reports}

Another way to communicate with the families is to send home progress reports. These can be done as frequently as once a week or as infrequently as once a month. They offer family members a systematic way of getting information about the accomplishments of their children. One way to go about this is to have students keep a log of activities for the day and provide a place for family members to sign the activity or have teachers put an entry in the log and have the parents sign the log.

\section{Occasional Notes Home}

Teachers also can send notes that point out a child's unique accomplishments. These notes could be simple forms of communication such as "happy grams," which talk about a specific accomplishment, or a little sticker that the child can wear home. The notes may be simple and brief, mentioning something the child has done that the families might like to hear about.

\section{Telephone Conferences}

Communicating by way of the telephone should be reserved for short conversations. Long conversations are better done in person and are not appropriate by telephone. Although the telephone is convenient and can be useful in addressing family concerns quickly, it precludes nonverbal messages. When calling a family member, the caller should always identify himself or herself and ask if this is a convenient time to talk. The telephone should not be a regular means to relate negative information about the child. Those communications are delicate and require great effort to ensure good communication. When sending delicate messages, eye contact and the body language of the parent aid communication. Telephone calls should be planned carefully, and the key issues jotted down prior to making the call. In doing this, you can concentrate on the conversation and ensure that you don't forget to bring up an important item. Parents should be allowed time to respond to or answer questions.

\section{FORMAL FAMILY CONFERENCES}

In virtually all schools in the United States, conferences are the primary vehicle to communicate with families. Conferences with family members are held to accomplish the following (Turnbull \& Turnbull, 2001):
1. To share information about the home and school environment.

2. To work together to help the child develop and share information on the child's progress.

3. To develop rapport and mutual commitment to the child's optimal development.

4. To cooperate in alleviating problems or concerns.

Turnbull and Turnbull (2001) also identify three phases to follow in planning and carrying out a conference: (a) preconference planning, (b) conference implementation, and (c) postconference follow-up.

\section{Preconference Planning}

Good planning can help ensure a successful conference. Kroth (1985) identifies three basic steps to a preconference: (a) notify, (b) prepare, and (c) arrange.

\section{Notify}

The first step in preconference planning is to notify key family members of the upcoming conference. Sometimes schools have predetermined conference procedures, including scheduling conference time and space and sending notification through school calendars and reminders that the conference will be held. Each family must be considered, and individual strategies developed when needed, to ensure that family members are aware of the conference and able to attend. The notification must be as nonthreatening as possible. If parents feel threatened, they may find a convenient reason for not attending the conference. School personnel also can alleviate anxiety by being as clear as possible about the purpose of the conference. In schools with large populations of students whose families' first language is not English, all materials must be translated into the appropriate languages.

\section{Prepare}

In preparing for the conference, you must be well aware of the issues to be addressed. Several steps may be considered (Turnbull \& Turnbull, 2001).

1. Prior to the visit review the student's cumulative folder and samples of student work that indicate progress, such as portfolios.

2. Have a clear assessment as to the student's current progress or the issue to be addressed.

3. Have examples of the student's work.

4. Prepare an outline of topics to be addressed.

5. When appropriate, meet with other professionals to gain additional information about the child.

\section{Arrange}

The final step in the preconference is to prepare the environment. Consider implementing the following (Turnbull \& 
Turnbull, 2001):

1. If no one else will be in the classroom, it is an ideal place because it enables families to see the context of their child's learning. If the classroom is equipped with only small chairs, however, consider bringing in a table to sit around, or meet in another room. Having adults sit on small chairs is uncomfortable and can be distracting.

2. Gather all the important information prior to the meeting so you are ready to go when the family members arrive.

3. Try to schedule a time or place where interruptions are unlikely.

4. Make sure the room is comfortable. An uncomfortable setting can inhibit concentration and communication.

5. If the topic for discussion is sensitive, have tissues available in case someone becomes emotional during the meeting.

6. If the family does not speak English fluently, provide for an interpreter.

\section{Conducting the Conference}

In conducting any conference, good communication skills are essential. Start with broad opening statements and do not get into the essence of the information too quickly. Use active listening to help clarify the issues and concerns that family members raise. Follow the agenda and do not allow the conference to stray. If critical new information is raised at the conference, make a judgment as to the merit of changing the planned agenda to address the new information. Make every effort to adjust when needed without becoming so distracted that the task at hand gets lost. Once the conference is over, summarize it so everybody knows what was decided in the conference.

\section{Postconference Follow-Up}

Depending on the purpose and length of the conference, summarizing the notes and providing a written copy to participants is a good way to facilitate understanding and to ensure that everyone has the same interpretation of the meeting. Depending on the outcomes of the conference, the teacher might want to make a follow-up phone call to the family to see how the implementation of any plan is progressing. Also, it's a good idea to follow up with other key members to see if any new information or new actions have to be developed.

\section{Unplanned Conferences}

Unplanned conferences with family members will inevitably arise (Turnbull \& Turnbull, 2001). Recognizing this reality, these unplanned conferences should be anticipated, and some actions thought through before they take place. Although it is unrealistic to expect that as a teacher you will never be caught off guard, you can do some things to help you to be ready for an unexpected conference.

First, keep good data on the students in your classes. If your files are well organized, you can quickly retrieve the information needed to answer questions. If you are asked a specific question and you don't have the information, it is better to tell the family members that you don't have the information readily at hand but will get it and get back to them immediately than to bluff a response. You might even want to anticipate being caught off guard and come up with a standard phrase such as, "I'm really glad you took the time to talk to me. Let me make sure I get the right information for you and get back to you as soon as possible."

At times, however, parents may come to see you because they are upset about something their child has said or something that has happened in your class or in the school. Unfortunately, the parent may be very angry when he or she approaches you. You must not do anything to escalate the situation. In this case, here are some things you can do to help deflate the aggression:

1. Listen! Do not try to interrupt the family members. Let them get off their chest whatever they came to say.

2. Don't argue, don't become defensive, and don't try to promise something that you may not be able to deliver.

3. Write down the key phrases, and when the family member calms down, repeat these phrases to him or her to be sure you have heard the concerns accurately. Then tell him or her that you will try to get the information needed and schedule a meeting with the appropriate individuals to address their concerns.

4. Speak softly. This often calms family members and encourages them to tone down their voice.

Most unplanned conferences are pleasant occasions for sharing information spontaneously. Although you certainly are likely to encounter upset family members, this type of unplanned conference is the exception rather than the norm.

\section{WORKING WITH FAMILIES- WELL WORTH THE EFFORT}

Without an active partnership with families, schools always will be limited in what we are able to accomplish. Developing partnerships is one of the most important goals that our schools can undertake. Most of the individual primary needs of our students are met through their families. A collaborative school must include active partnerships with families. Our students are all members of families first and students second. Consequently, families are going to have the most lasting and powerful influence on their development. Forming meaningful partnerships with families is one of the most important collaborative partnerships teachers can develop. 


\section{REMEMBER ...}

As you work to develop these partnerships, remember:

1. The family is the basic unit of our society.

2. Family configurations in our culture are diverse, and teachers must be cognizant of this diversity. Also important to consider are the values, decision-making styles, family roles, languages, background knowledge, and influences of significant others (Turnbull \& Turnbull, 2001).

3. Families are complex systems made up of a series of subsystems. Anything that impacts any subsystem will impact the entire system.

4. One of the biggest challenges in forming strong school-family collaboration is to ensure that school personnel confront their own stereotypes regarding families of students whose race, ethnicity, socioeconomic level, or language differs from their own.

5. The tasks in which families engage to meet the needs of members of the family are called family functions. The seven family functions are: (a) economic, (b) domestic and health care, (c) socialization, (d) recreational, (e) self-definition, (f) affection, and (g) educational/vocational.

6. The extent of cohesiveness and adaptability of the family has a significant impact on interactions within the family system. Cohesion represents the emotional bonds between members of the family. Adaptability is the capacity of a family to change in response to outside pressures.

7. Families have identified logistics, communication problems, and misunderstanding of schools as concerns that inhibit their ability to be full partners with schools.

8. Professionals have identified parental apathy, lack of time, and the expertise of professionals as concerns that inhibit their ability to be full partners with families.

9. Once a sound relationship is established at the start of the year, other strategies for ways to communicate with parents must be developed. These include: (a) handbooks, (b) announcements for specific situations, (c) newsletters, (d) regular progress messages, (e) occasional notes, and (f) telephone conferences.

10. One important way to communicate with families is through conferences. In planning and carrying out a conference, the three phases that should be followed are: (a) preconference planning, (b) conference implementation, and (c) postconference follow-up.

\section{ACTIVITIES}

1. Break up the class into several groups. Assign each group one or more of the areas of family functioning. Ask each group to develop strategies the school can use to help the family within the areas of family functioning assigned to the group.

2. Have each class member plan and implement a mock conference with a family member. The conference could be videotaped for small-group discussion and peer feedback. If students have their own class or are in a practicum experience, the conference could be real instead of mock.

3. Have students identify a traditional, blended, and single-parent family that has school-age children. Have the students interview the adults in these families to get a sense of their experience with schools and how their unique family configuration inhibits or enhances their experiences.

4. Have students design a brief questionnaire or set of interview questions regarding family perceptions of their relationship to the school. Include questions about the resources that family might represent. Have the students work in groups and present their findings to the class.

5. If students have their own class or are in a practicum experience, have them implement and evaluate one or more of the strategies other than a conference for communicating with families.

\section{REFERENCES}

Barnett, W. S., \& Boyce, G. C. (1995). Effects of children with Down syndrome on parents' attitude. American Journal on Mental Retardation, $100(2), 115-127$.

Beirne-Smith, M., Ittenbach, R. F., \& Patton, J. R. (1998). Mental retardation (5th ed.). Columbus, OH: Merrill/Prentice-Hall.

Edwards, R. (1995, September). Psychologists foster the new definition of family. APA Monitor, p. 38.

Kroth, R. L. (1985). Communicating with parents of exceptional children: Improving parent-teacher relationships ( $2 \mathrm{~d}$ ed.). Denver: Love Publishing.

Luterman, D. (1991). Counseling and the diagnostic process. Counseling the communicatively disordered (pp. 80-82). Austin, TX: Pro-Ed.

Lynch, E. W., \& Stein, R. (1987). Perspectives on parent participation in special education. Exceptional Education Quarterly, 3(2), 56-63.

Moles, O. C. (1993). Collaboration between schools and disadvantaged parents: Obstacles and openings. In N. F. Chavkin (Ed.), Families and schools in a pluralistic society (pp. 21-51). Albany: State University of New York Press.

Moll, L. C., Amanti, C., Neff, D., \& Gonzalez, N. (1992). Funds of knowledge and teaching:Using a qualitative approach to connect homes and classrooms. Theory Into Practice, 3I(2), 132-141.

Olson, R. A. (1980). Evaluation as interaction in support of change. Grand Forks, ND: University of North Dakota.

Powell, T. H., \& Gallagher, P. A. (1993). Brothers and sisters: A special part of exceptional families ( $2 \mathrm{~d}$ ed.). Baltimore: Paul H. Brookes.

Scoon-Rogers, L. (1999). Child support for custodial mothers and fathers: 1995. U.S. Census Bureau Current Population Reports (Publication No. P60-196). U.S. Department of Commerce.

Turnbull, A. P., \& Turnbull, H. R. III. (2001). Families, professionals, and exceptionality: Collaborating for empowerment (4th ed.). Columbus, OH: Merrill/Prentice Hall.

Turnbull, A. P., Turnbull, H. R., Shank, M., \& Leal, D. (1995). Exceptional lives: Special education in today's schools. Englewood Cliffs, NJ: Merrill/ Prentice-Hall.

Zinn, J. E., \& Eitzen. (1993). Diversity in families (3d ed.). New York: HarperCollins. 